\title{
A Novel Sintered Stainless Steel Fiber Felt with Rough Surface Morphologies
}

\author{
Chaobin Fang, Zhenping Wan, Bin Liu, and Longsheng Lu \\ Key Laboratory of Surface Functional Structure Manufacturing of Guangdong Higher Education Institutes, \\ South China University of Technology, Guangzhou 510640, China
}

Correspondence should be addressed to Zhenping Wan; zhpwan@scut.edu.cn

Received 6 August 2014; Accepted 21 October 2014; Published 13 November 2014

Academic Editor: Wei Zhou

Copyright (C) 2014 Chaobin Fang et al. This is an open access article distributed under the Creative Commons Attribution License, which permits unrestricted use, distribution, and reproduction in any medium, provided the original work is properly cited.

A novel sintered stainless steel fiber felt (SSSFF) with rough surface morphologies and high strength as well as high porosity is fabricated by solid-state sintering of stainless steel fibers produced by cutting method. The rough surface morphologies are characterized by laminar and jagged structures formed on the surface of stainless steel fibers. The SSSFF with $85 \%$ porosity sintered at $1200^{\circ} \mathrm{C}$ for $60 \mathrm{~min}$ exhibits tensile strength of $19 \mathrm{MPa}$ and yield stress of $10.5 \mathrm{MPa}$. The influence of sintering parameters on surface morphologies and tensile strength is investigated. The experimental results show that the rough surface structures will disappear gradually when sintering temperature is $1300^{\circ} \mathrm{C}$ or sintering time is excessive, that is, $240 \mathrm{~min}$ when sintering temperature is $1200^{\circ} \mathrm{C}$. The SSSFF with high porosity presents high tensile strength when sintering temperature ranges from $1100^{\circ} \mathrm{C}$ to $1200^{\circ} \mathrm{C}$ and sintering time is from $60 \mathrm{~min}$ to $120 \mathrm{~min}$. In addition, the fracture mechanism of the SSSFF is investigated when subjected to uniaxial tensile load.

\section{Introduction}

As advanced structural and functional materials, sintered stainless steel fiber felt (SSSFF) has been widely applied to sound absorption, phase change heat transfer, and energy absorption [1], jet noise reduction [2], gas diffusion layer $[3,4]$ of fuel cell, catalyst support for volatile organic compounds removal [5], and bioimplants [6] owning to three-dimensional network structure, perfect permeability, good thermal stability, outstanding corrosion resistance, and biocompatibility. With the extension of applications, some special requirements for the properties of SSSFFs, such as rough surface and high strength as well as high porosity, are demanded. For example, the rough surface can promote adhesive strength of the primer to the support while using SSSFFs as combustion catalyst supports to disperse active phase [7]. What is more, the SSSFFs used to combustion catalyst support should possess high strength as well as high porosity since the supports have to bear impact of high-speed gas stream and, at the same time, must exhibit low pressure drop [8]. Another example is the application of SSSFFs in bioimplants where monocyte adhesion and inflammatory cytokine production depend on biomaterial properties, such as surface roughness and surface area $[6,9]$.

On the porosity and strength of SSSFFs, a lot of work has been done to tailor the porous structure and the mechanical properties. Qiao et al. [10] investigated the influence of porosity on quasi-static compressive properties of the porous metal media using bundle-drawn stainless steel fibers. The compressive yield stress of the SSSFFs with $82.3 \%$ porosity is about $4 \mathrm{MPa}$. Clyne et al. [11] measured the yield stress of bonded networks of metal fibers using melt-extracted ferritic stainless steel fibers. The yield stress of SSSFFs with $85 \%$ porosity and fiber segment aspect ratio of 6 is about $1 \mathrm{MPa}$. Markaki et al. [12] prepared highly porous material by liquid phase sintering of short stainless steel fibers and the tensile strength was less than $1 \mathrm{MPa}$. Ducheyne et al. [13] fabricated porous material with low porosity ranging from $20 \%$ to $58 \%$ by sintering $316 \mathrm{~L}$ stainless steel fiber. The tensile strength of the SSSFFs made of $100 \mu \mathrm{m}$ diameter fibers with $57.3 \%$ porosity is $52 \mathrm{MPa}$. From the above investigation, the strength of SSSFFs with high porosity is very low. In addition, the currently available SSSFFs are made of melt-extracted or bundle-drawn stainless steel fibers. The surface of stainless 


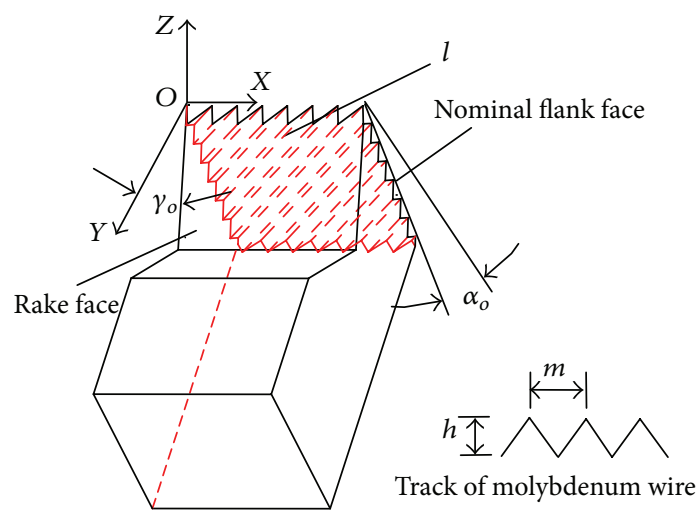

FIGURE 1: Schematic drawing of multitooth tool.

steel fiber fabricated by melt-extraction $[14,15]$ or bundledrawing $[16,17]$ is very smooth. Therefore, preparation of SSSFFs with rough surface and high strength as well as high porosity is a stringent technical demanding.

The present study aims to develop a novel SSSFF with rough surface and high strength as well as high porosity using stainless steel fiber manufactured by cutting method. The effects of sintering parameters on surface morphologies are investigated. And also, the influence of sintering parameters and porosity on tensile properties of SSSFF is presented in order to obtain high strength as well as high porosity. In addition, fracture mechanisms of the novel SSSFF are investigated under uniaxial tensile loading.

\section{Experimental Procedures}

2.1. Manufacturing Process of Stainless Steel Fiber. The manufacturing of stainless steel fiber is conducted on precise lathe C6132A using a self-designed multitooth tool as shown in Figure 1. A row of tiny teeth with triangular cross-section is machined out in the nominal flank face. While making the multitooth tool, the tool is rotated $45^{\circ}$ around the $y$ axis counterclockwise. The parameters of a tiny tooth are $m$ and $h$ measured in cross-section. In Figure $1, \gamma_{o}$ and $\alpha_{o}$ are nominal rake angle and clearance angle, respectively. The tool is installed by rotating $45^{\circ}$ around the $y$-axis counterclockwise so that the line $l$ does not exert intervention during cutting. Stainless steel $1 \mathrm{Cr} 18 \mathrm{Ni} 9 \mathrm{Ti}$ is used as workpiece with diameter of $65 \mathrm{~mm}$. Several long stainless steel fibers with equivalent diameter of $100 \mu \mathrm{m}$ are produced simultaneously since several tiny teeth are involved in cutting at the same time. According to previous experimental results [18], the parameters of the multitooth tool used in this study are $m=$ $0.3 \mathrm{~mm}, h=0.2 \mathrm{~mm}, \gamma_{o}=30^{\circ}$, and $\alpha_{o}=8^{\circ}$. The cutting depth is $0.2 \mathrm{~mm}$, feed is $0.2 \mathrm{~mm} / \mathrm{r}$, and cutting speed is $10 \mathrm{~m} / \mathrm{min}$.

2.2. Sintering Process of the SSSFF. The sintering process of SSSFF can be divided into following four steps: fiber chipping, mold-pressing, sintering, and cooling. The long stainless steel fibers manufactured by the above cutting method are segmented into short fibers with length of $10-20 \mathrm{~mm}$. The short fibers are placed in a mold cavity layer by layer in random distribution. Pressure is exerted on the mold by bolts. Thus, the semifinished SSSFF sample is obtained in the shape of the mold chamber. The sintering is carried out in a vacuum furnace in order to prevent oxidation and decarburization of stainless steel fiber during high temperature sintering. The heating rate is kept at $300^{\circ} \mathrm{C} / \mathrm{h}$ when the temperature is below $800^{\circ} \mathrm{C}$, while reduced to $200^{\circ} \mathrm{C} / \mathrm{h}$ as the temperature is above $800^{\circ} \mathrm{C}$. After sintering at a constant temperature, the cooling rate is $400^{\circ} \mathrm{C} / \mathrm{h}$. A scanning electron microscope (SEM) S$3700 \mathrm{~N}$ is used to observing the morphologies of the SSSFFs. The average porosity $\theta$ of SSSFF can be calculated directly by quality-volume method with the following formula [19]:

$$
\theta=1-\frac{M}{\rho V},
$$

where $V$ is the volume of SSSFF $\left(\mathrm{cm}^{3}\right), M$ is the mass of SSSFF $(\mathrm{g})$, and $\rho$ is the density of stainless steel $\left(\mathrm{g} / \mathrm{cm}^{3}\right)$.

2.3. Tensile Test of the SSSFF. The tensile test is carried out on a universal material testing machine (INSTRON2369, USA) at room temperature. The sample dimension of SSSFF is $105 \mathrm{~mm} \times 15 \mathrm{~mm} \times 2 \mathrm{~mm}$. To avoid the deformation of the SSSFF network structure in the clamping process, rubber mats are placed between clamps before tensile testing. All the samples are pulled to fracture at a constant tensile rate of $1.5 \mathrm{~mm} / \mathrm{min}$. Strain is defined as the ratio between the sample elongation and the initial gauge length. The tensile stress is calculated by using pulling force and the initial section of the sample. The stress and strain are recorded throughout the pulling process and then the stress-strain curves are obtained.

\section{Surface Morphologies of the SSSFF}

3.1. Characteristics of Surface Morphologies. The surface morphologies of the SSSFF sample before and after being sintered are shown in Figure 2. It can be seen from Figure 2 that the rough surface morphologies characterized by laminar and jagged structures are the unique features of the SSSFFs compared with other sintered porous metals using meltextracted and bundle-drawn stainless steel fibers. The laminar and jagged surface can provide higher specific surface area and promote adhesive strength of the primer to the metallic support while using the SSSFFs as catalyst supports to disperse active phase. Also, the rough surface can favor bone anchoring and improve the mechanical interlocking at the bone-implant interface when the SSSFFs are used to bioimplants. Comparing the surface morphologies of SSSFF sample before sintered with that of SSSFF sintered at $1100^{\circ} \mathrm{C}$ for $60 \mathrm{~min}$, it can be found that the rough surface features have been retained after sintered. In addition, the contact points among fibers are transformed into sintering joints after being sintered and the sintered SSSFF is more compact and solid. The pores formed among randomly distributed fibers and different sintering joints, such as intercrossed joint points and line points, exhibit irregular and three-dimensionally interconnected structure. Therefore, the porosity of the SSSFF can be tailored at a wide range (60-95\%) by changing quality of fibers and mold-pressure. 


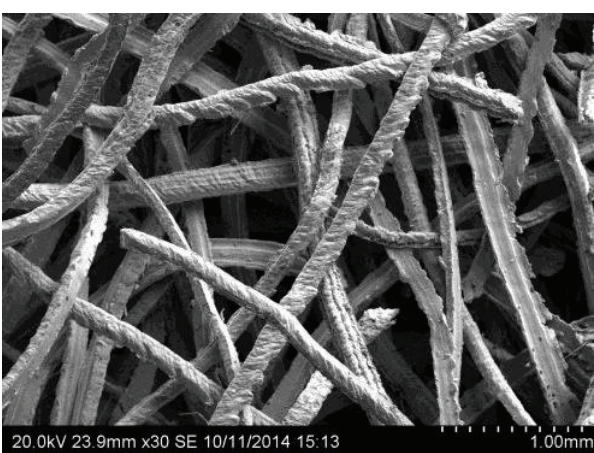

(a)

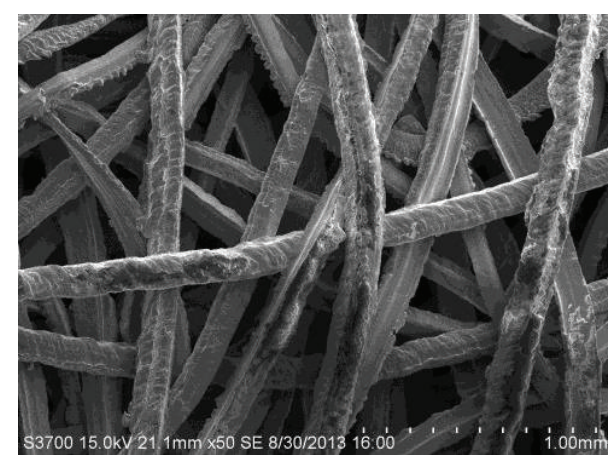

(b)

FIGURE 2: SEM images of (a) SSSFF before sintering and (b) SSSFF sintered at $1100^{\circ} \mathrm{C}$ for $60 \mathrm{~min}$.

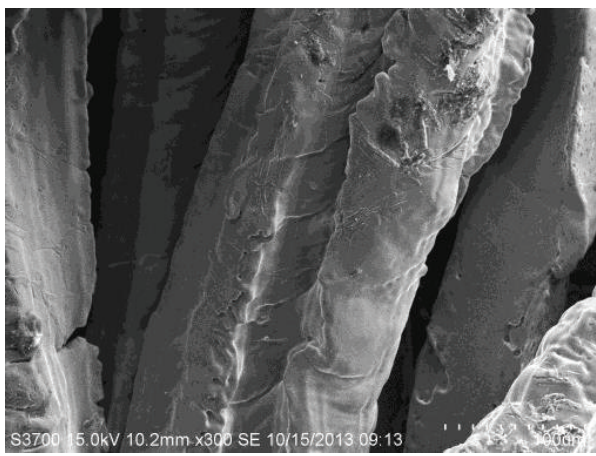

(a)

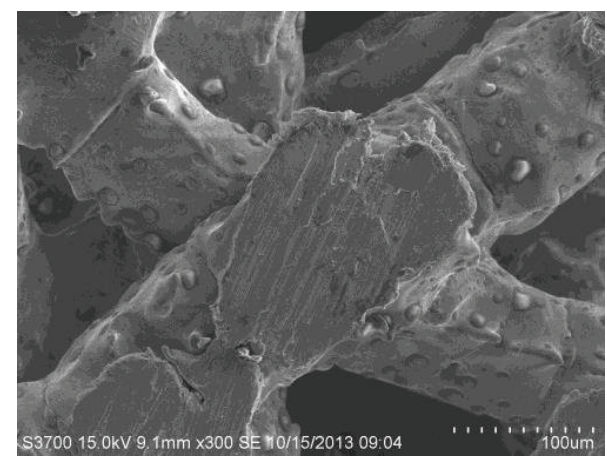

(b)

FIGURE 3: Surface morphologies of SSSFF sintered $60 \mathrm{~min}$ (a) at $1200^{\circ} \mathrm{C}$ and (b) at $1300^{\circ} \mathrm{C}$.

3.2. Influence of Sintering Temperature on Surface Morphologies. Sintering temperature has significant influence on surface morphologies of SSSFFs. Figures 3(a) and 3(b) show the surface morphologies of SSSFFs sintered $60 \mathrm{~min}$ at $1200^{\circ} \mathrm{C}$ and $1300^{\circ} \mathrm{C}$, respectively. Comparing Figure 2(b) and Figures 3 (a) and 3(b), it can be found that the remaining laminar and jagged structures are clearly visible when sintering temperature is $1100^{\circ} \mathrm{C}$ and $1200^{\circ} \mathrm{C}$. However, melting phenomenon occurs when sintering temperature is $1300^{\circ} \mathrm{C}$. At this time, the laminar and jagged structures have disappeared and the surface morphologies of SSSFF become smooth. Thus, the sintering temperature should be no more than $1200^{\circ} \mathrm{C}$ in order to prepare SSSFFs with rough surface morphologies.

\subsection{Influence of Sintering Time on Surface Morphologies.} Figures 4(a) and 4(b) present the surface morphologies of SSSFFs sintered at $1200^{\circ} \mathrm{C}$ for $120 \mathrm{~min}$ and $240 \mathrm{~min}$, respectively. From Figures 3(a) and 4(a), the rough surface of SSSFFs is very distinct. From Figure 4(b), it can be found that the surface morphologies of SSSFF are slick and the laminar and jagged structures disappeared. Therefore, the sintering time should be no longer than 120 min to maintain the rough surface of SSSFFs. It is worth pointing out that some particles form on the surface of the fiber as shown in Figures 3(b) and 4(b) when the sintering temperature is $1300^{\circ} \mathrm{C}$ or sintering time is excessive, for example, $240 \mathrm{~min}$ at
TABLE 1: $\mathrm{Mn}, \mathrm{Cr}$, and $\mathrm{O}$ contents of stainless steel fiber surface and particles.

\begin{tabular}{|c|c|c|c|c|}
\hline Sites & Sintering conditions & $\mathrm{Cr}(\%)$ & Mn (\%) & $\mathrm{O}(\%)$ \\
\hline Particles & $\begin{array}{c}\text { Sintered at } 1300^{\circ} \mathrm{C} \text { for } \\
60 \mathrm{~min}\end{array}$ & 6.92 & 41.89 & 35.34 \\
\hline Particles & $\begin{array}{l}\text { Sintered at } 1200^{\circ} \mathrm{C} \text { for } \\
240 \mathrm{~min}\end{array}$ & 26.37 & 13.22 & 51.39 \\
\hline Fiber surface & Before sintering & 16.87 & 0.95 & \\
\hline Fiber surface & $\begin{array}{l}\text { Sintered at } 1200^{\circ} \mathrm{C} \text { for } \\
60 \mathrm{~min}\end{array}$ & 17.45 & 0.94 & \\
\hline Fiber surface & $\begin{array}{l}\text { Sintered at } 1100^{\circ} \mathrm{C} \text { for } \\
60 \mathrm{~min}\end{array}$ & 16.08 & 0.83 & \\
\hline
\end{tabular}

$1200^{\circ} \mathrm{C}$. The chemical compositions of the particles are listed in Table 1. It is found from Table 1 that the particles are Mn and $\mathrm{Cr}$ precipitations. Owning to their high saturated vapor pressure, $\mathrm{Mn}$ and $\mathrm{Cr}$ precipitate readily from surface layer at exceedingly high sintering temperature or excessive sintering time. The precipitated $\mathrm{Mn}$ and $\mathrm{Cr}$ combine easily with $\mathrm{O}$ to form oxidizing materials since $\mathrm{Mn}$ and $\mathrm{Cr}$ have a strong affinity for Oxygen. Thus, the $\mathrm{O}$ contents of the precipitations are very high. In addition, from Table 1 , the $\mathrm{Mn}, \mathrm{Cr}$, and $\mathrm{O}$ contents of surface of fiber sintered at $1100^{\circ} \mathrm{C}$ for $60 \mathrm{~min}$ or at $1200^{\circ} \mathrm{C}$ for $60 \mathrm{~min}$ are consistent with that of fiber surface 


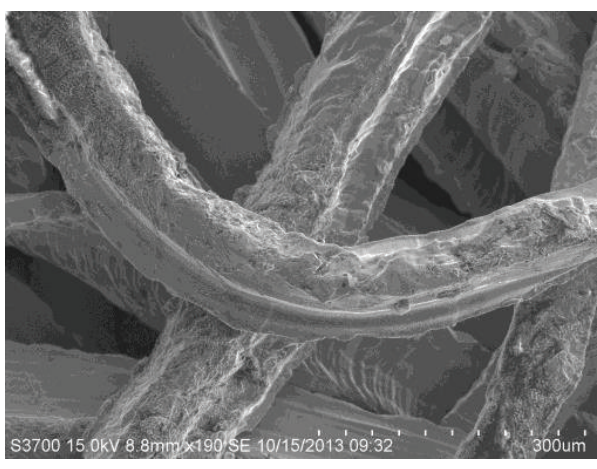

(a)

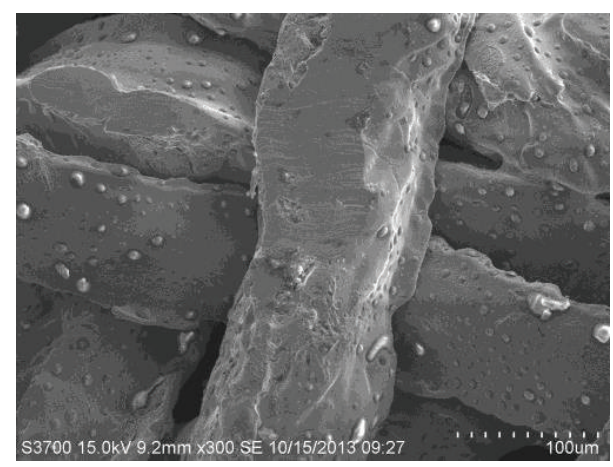

(b)

FIGURE 4: Surface morphologies of SSSFF sintered at $1200^{\circ} \mathrm{C}$ (a) for $120 \mathrm{~min}$ and (b) for $240 \mathrm{~min}$.

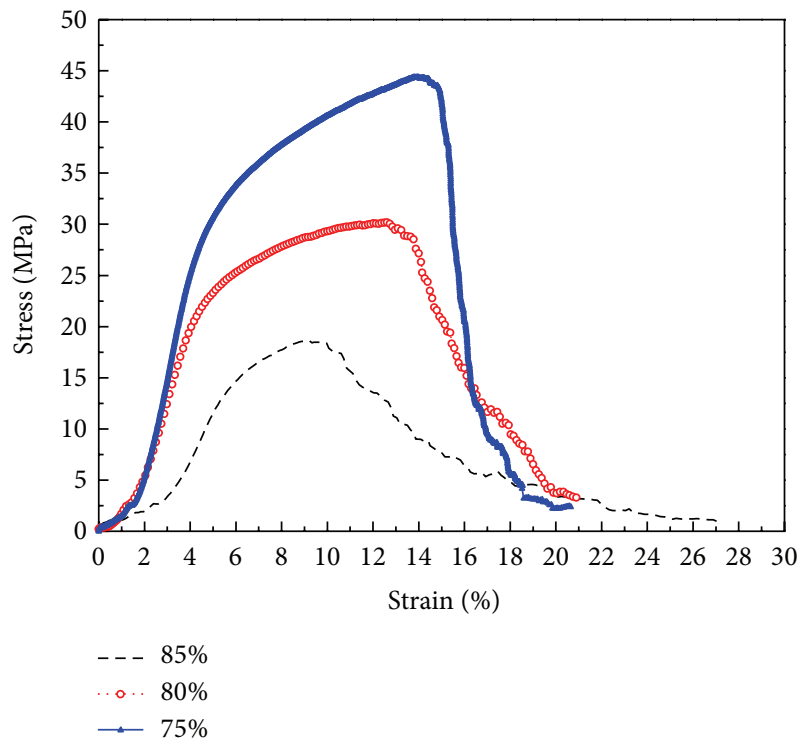

FIGURE 5: Tensile stress-strain curves of the SSSFF with different porosities (sintered at $1200^{\circ} \mathrm{C}$ for $60 \mathrm{~min}$ ).

before sintering. It is suggested that no $\mathrm{Mn}$ and $\mathrm{Cr}$ precipitate out from surface layer. In this case, no particles form on the surface of fiber.

\section{Effect of Porosity and Sintering Parameters on Tensile Strength}

4.1. Tensile Strength of the SSSFF with Different Porosities. Porosity as an important parameter of the SSSFF has great influence on the tensile strength. The tensile stress-strain curves of the SSSFF with various high porosities are shown in Figure 5 where the SSSFF samples were sintered at $1200^{\circ} \mathrm{C}$ for $60 \mathrm{~min}$. The SSSFF samples go into linear elastic range after experiencing a short-term initial nonlinear elastic deformation and then enter plastic deformation and hardening range. From Figure 5, the tensile strength of SSSFF samples with $75 \%, 80 \%$, and $85 \%$ porosity reaches $44.5 \mathrm{MPa}, 30.5 \mathrm{MPa}$, and $19 \mathrm{MPa}$, respectively. The yield stress of SSSFF samples with

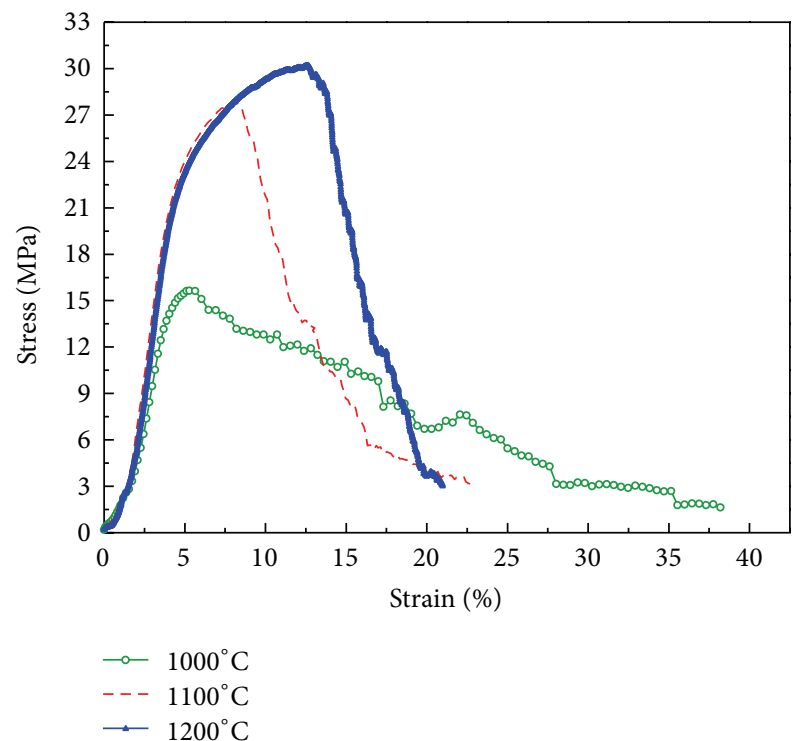

FIgURE 6: Tensile stress-strain curves of the SSSFF with $80 \%$ porosity sintered $60 \mathrm{~min}$.

$75 \%, 80 \%$, and $85 \%$ porosity achieves $25 \mathrm{MPa}, 17.5 \mathrm{MPa}$, and $10.5 \mathrm{MPa}$, respectively. It can be seen that the tensile strength and yield stress of the SSSFFs are far beyond that of SSSFFs prepared by Clyne et al. [11] and Markaki et al. [12]. Thus, this kind of SSSFFs possesses high strength as well as high porosity. The reason may be that the laminar and jagged surface structures increase the friction between fibers and provide occlusal force to hook fibers together, which are in favor of strong sintering joints forming.

4.2. Effect of Sintering Parameters on Tensile Property of the SSSFF. As important manufacturing parameters, sintering temperature and sintering time have a great influence on the forming process of the SSSFFs.

4.2.1. Sintering Temperature. The tensile stress-strain curves of SSSFF samples with $80 \%$ porosity sintered at $1000^{\circ} \mathrm{C}$, $1100^{\circ} \mathrm{C}$, and $1200^{\circ} \mathrm{C}$, respectively, for $60 \mathrm{~min}$ are shown in Figure 6. The tensile strengths of the samples sintered 


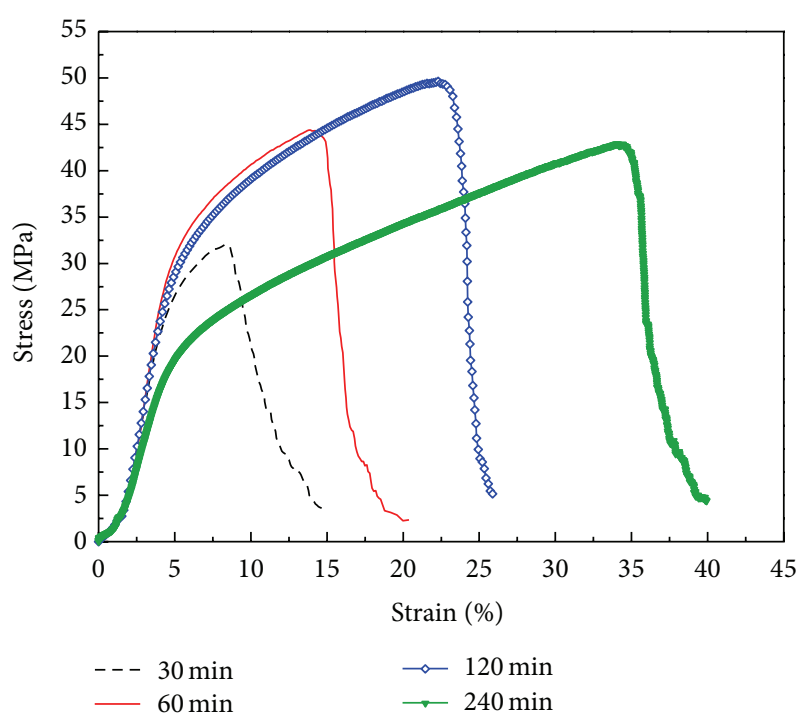

FIGURE 7: Tensile stress-strain curves of the SSSFF with 75\% porosity sintered at $1200^{\circ} \mathrm{C}$.

at $1000^{\circ} \mathrm{C}, 1100^{\circ} \mathrm{C}$, and $1200^{\circ} \mathrm{C}$ are $16 \mathrm{MPa}, 28.2 \mathrm{MPa}$, and $30.5 \mathrm{MPa}$, respectively. With the increase of sintering temperature, material migration becomes active, thereby promoting the formation of sintering joints, which makes bonding of interfiber stronger. Furthermore, the yield stress of samples sintered at $1000^{\circ} \mathrm{C}$ is $13.3 \mathrm{MPa}$ and the yield stresses of samples sintered at $1100^{\circ} \mathrm{C}$ and $1200^{\circ} \mathrm{C}$ are almost identical and reach $17.5 \mathrm{MPa}$. So, it can be concluded that the sintering temperature should range from $1100^{\circ} \mathrm{C}$ to $1200^{\circ} \mathrm{C}$ to obtain high strength.

4.2.2. Sintering Time. The tensile stress-strain curves of samples with $75 \%$ porosity sintered at $1200^{\circ} \mathrm{C}$ for $30 \mathrm{~min}, 60 \mathrm{~min}$, $120 \mathrm{~min}$, and $240 \mathrm{~min}$, respectively, are shown in Figure 7. The tensile strength increases from $33 \mathrm{MPa}$ to $49.5 \mathrm{MPa}$ with sintering time increasing from $30 \mathrm{~min}$ to $120 \mathrm{~min}$. However, the tensile strength decreases to $42.8 \mathrm{MPa}$ when prolonging sintering time excessively to $240 \mathrm{~min}$. It can be seen that prolonging the sintering time appropriately can promote the formation and growth of sintering joints since material of contact regions among fibers has enough time to diffuse and the tensile strength is improved. However, excessive sintering time makes grains coarsening, which leads to tensile strength decrease and elongation increase. In addition, the yield stresses of samples sintered for $60 \mathrm{~min}$ and $120 \mathrm{~min}$ are almost identical and up to $25 \mathrm{MPa}$. Thus, the appropriate sintering time should be between $60 \mathrm{~min}$ and $120 \mathrm{~min}$.

\section{Fracture Mechanism Analysis}

So far, the fracture mechanism of SSSFFs has not been investigated deeply under tensile loading. But, the fracture mechanism is important to tailor the mechanical properties of SSSFFs. It is suggested by experimental observations that there are two fracture modes for the SSSFF: sintering joint breaking and fiber filament fracture.

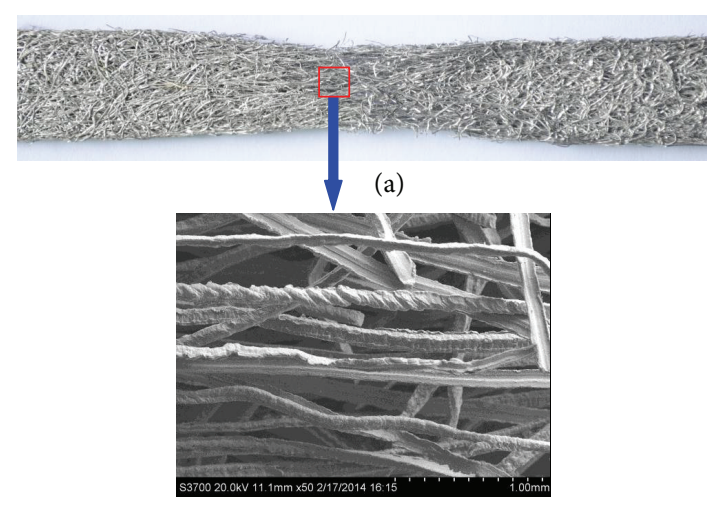

(b)

FIGURE 8: Failed sample with $80 \%$ porosity sintered at $1000^{\circ} \mathrm{C}$ for 60 min after tension test. (a) Fracture appearance, (b) SEM image of fracture region.

5.1. Sintering Joint Breaking. Figure 8 shows the fracture morphology of SSSFF sample with $80 \%$ porosity sintered at $1000^{\circ} \mathrm{C}$ for $60 \mathrm{~min}$. It clearly shows from Figure 8 that most of the randomly distributed fibers at fracture region are oriented to the tensile direction with obvious network structure loosing and necking. Owing to high porosity and relatively low sintering temperature, the formation and growth of sintering joints in the three-dimensional reticulated skeleton of SSSFF become difficult, which results in low fiber-to-fiber bonding strength. On the other hand, SSSFFs are multilayer sintered three-dimensional network material by stacking randomly laid stainless steel fibers. Hence, the sintering joints are easily broken by shear stress under tension, which leads to low tensile strength of SSSFFs. In consequence, most of the randomly distributed fibers at fracture region rotate towards the tension direction without any obstacles owning to the sintering joints breaking. In addition, the fracture process is slow due to the resistance coming from fibers rotation, randomly orientational fibers alignment, and friction among fibers. Therefore, the sintering joints breaking by shearoff mechanism is an essential failure mode for the SSSFF under tension loading owing to high porosity, low sintering temperature, or short sintering time. In this case, the tensile strength of SSSFF is low.

5.2. Fiber Filament Fracture. Figure 9 shows the fracture morphologies of SSSFF sample with $75 \%$ porosity sintered at $1200^{\circ} \mathrm{C}$ for $60 \mathrm{~min}$. From Figure $9(\mathrm{a})$, necking phenomenon, network structure loosing, and fibers alignment cannot be observed. Owning to relatively low porosity, proper sintering temperature, and sintering time, the sintering joints among fibers can form and grow successfully, which results in strong interfiber joints. Fiber filament fracture occurs preferentially to joint rupture when tensile stress reaches its fracture strength as shown in Figure 9(b). Fiber filaments go through necking deformation and ductile fracture as shown in Figure 9(c). Since sintering joints are not broken, the randomly distributed fibers cannot rotate towards the tension direction without any obstacles and the three-dimensional network structure does not become loose. While reaching 


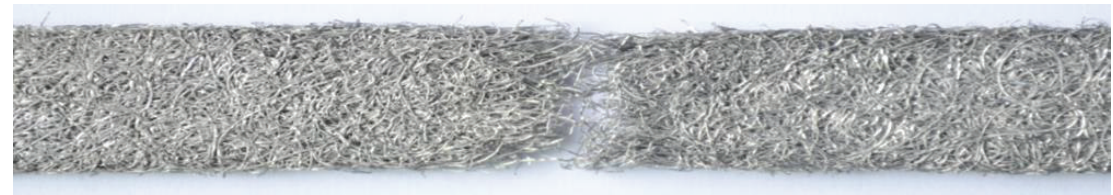

(a)

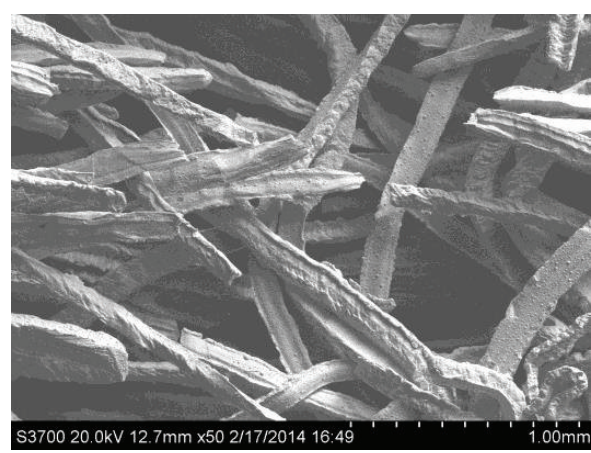

(b)

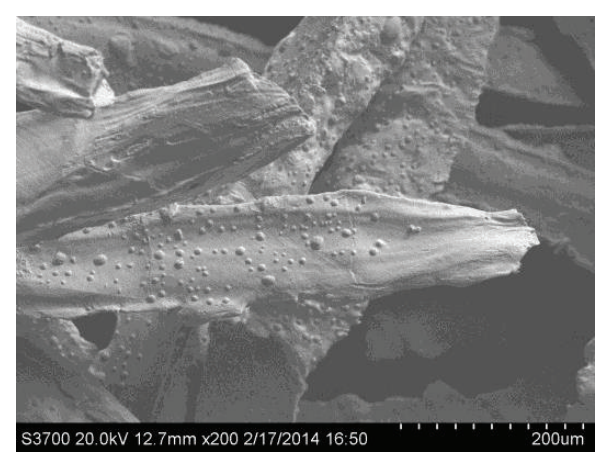

(c)

FIGURE 9: Failed sample with $75 \%$ porosity sintered at $1200^{\circ} \mathrm{C}$ for $60 \mathrm{~min}$ after tension test. (a) Fracture appearance, (b) SEM image of fracture region, and (c) fractured fiber with necking section.

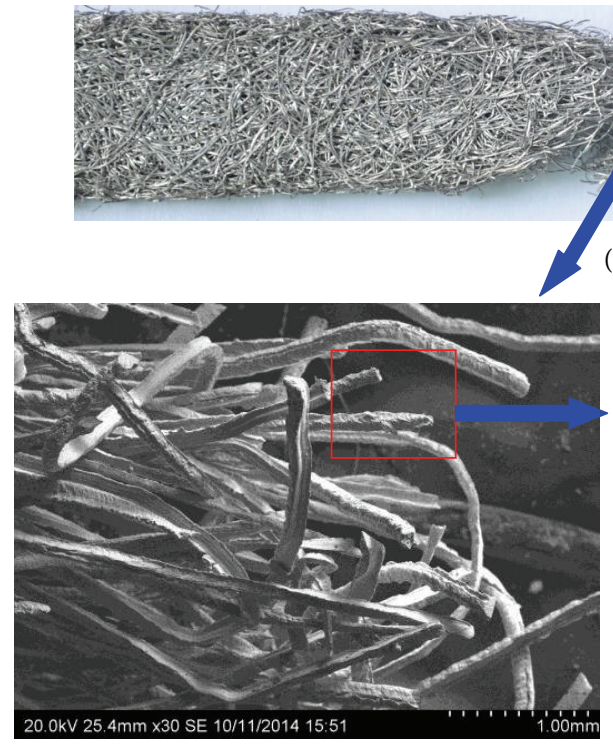

(b)

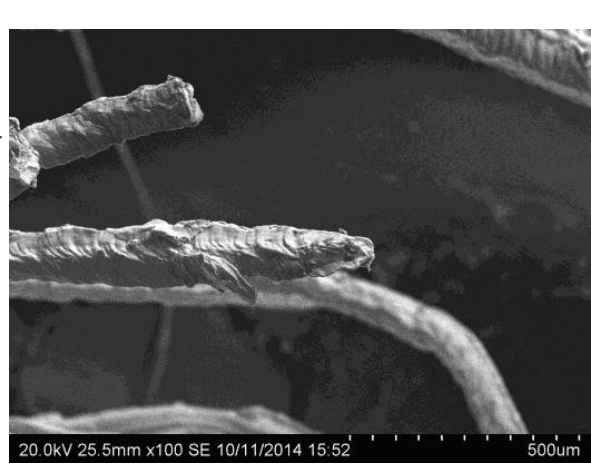

(c)

FIGURE 10: Failed sample with $80 \%$ porosity sintered at $1100^{\circ} \mathrm{C}$ for $60 \mathrm{~min}$. (a) Fracture appearance, (b) SEM image of fracture region, and (c) fractured fiber with necking section.

the tensile strength of SSSFF, the fracture of fiber filaments occurs in an instantaneous way, resulting in a sharp stress drop in the stress-strain curves. Therefore, it can be concluded that the fiber filaments fracture is the other essential failure mode for the SSSFF under tension loading owing to relatively low porosity, proper sintering temperature, and sintering time. In this case, the tensile strength of SSSFF is high.

5.3. Combined Fracture Mode. When tensile strength of SSSFF is low, the dominant fracture mode is sintering joint breaking, whereas the dominant fracture is fiber filament fracture when tensile strength of SSSFF is high. However, in most cases, the combined fracture mode is more prevalent. Figure 10 presents the fracture morphologies of SSSFF sample with $80 \%$ porosity sintered at $1100^{\circ} \mathrm{C}$ for $60 \mathrm{~min}$. It can be seen from Figure 10(a) that part of fibers is aligned and part of fibers is disorderly. From Figure 10(b), many fibers in fracture region are oriented to the tensile direction and the network structure becomes loose. It is suggested that sintering joint breaking is one of main fracture modes. From Figure 10(c), fiber necking deformation and ductile fracture are observed, which proves that fiber filament fracture is also one of the main fracture modes. 


\section{Conclusions}

(1) A novel SSSFF with rough surface morphologies and high strength as well as high porosity is fabricated. The rough surface morphologies characterized by laminar and jagged structures are the unique characteristics of the SSSFF.

(2) The tensile strength of SSSFF samples with 75\%, $80 \%$, and $85 \%$ porosity sintered at $1200^{\circ} \mathrm{C}$ for $60 \mathrm{~min}$ reaches $44.5 \mathrm{MPa}, 30.5 \mathrm{MPa}$, and $19 \mathrm{MPa}$, respectively. The yield stress of SSSFF samples with 75\%, 80\%, and $85 \%$ porosity achieves $25 \mathrm{MPa}, 17.5 \mathrm{MPa}$, and $10.5 \mathrm{MPa}$, respectively.

(3) The surface of the SSSFF becomes smooth when sintering temperature is $1300^{\circ} \mathrm{C}$ or sintering time is excessive, for example, $240 \mathrm{~min}$ at $1200^{\circ} \mathrm{C}$. In order to obtain SSSFFs with rough surface and high strength, the sintering temperature should range from $1100^{\circ} \mathrm{C}$ to $1200^{\circ} \mathrm{C}$ and sintering time should be between $60 \mathrm{~min}$ and $120 \mathrm{~min}$.

(4) There are two fracture mechanisms for the SSSFF under tension. Sintering joints breaking by shearoff is essential fracture mechanism owing to high porosity, low sintering temperature, or short sintering time, while the dominant fracture mechanism is fiber ductile fracture by tension when porosity is relatively low and sintering temperature and sintering time are proper. But in many cases, the SSSFF fails by the combined fracture modes.

\section{Conflict of Interests}

The authors declare that there is no conflict of interests regarding the publication of this paper.

\section{Acknowledgments}

This work is financially sponsored by the National Natural Science Foundation of China (no. 51375176) and supported by the Fundamental Research Funds for the Central Universities, SCUT (no. 2013ZZ017).

\section{References}

[1] Z. Xi, J. Zhu, H. Tang et al., "Progress of application researches of porous fiber metals," Materials, vol. 4, no. 4, pp. 816-824, 2011.

[2] J. C. Tan and T. W. Clyne, "Ferrous fibre network materials for jet noise reduction in aeroengines part II: thermo-mechanical stability," Advanced Engineering Materials, vol. 10, no. 3, pp. 201209, 2008.

[3] P. Y. Yi, L. F. Peng, X. M. Lai, M. T. Li, and J. Ni, "Investigation of sintered stainless steel fiber felt as gas diffusion layer in proton exchange membrane fuel cells," International Journal of Hydrogen Energy, vol. 37, no. 15, pp. 11334-11344, 2012.

[4] J. Liu, G. Sun, F. Zhao et al., "Study of sintered stainless steel fiber felt as gas diffusion backing in air-breathing DMFC," Journal of Power Sources, vol. 133, no. 2, pp. 175-180, 2004.
[5] I. Yuranov, A. Renken, and L. Kiwi-Minsker, "Zeolite/sintered metal fibers composites as effective structured catalysts," Applied Catalysis A: General, vol. 281, no. 1-2, pp. 55-60, 2005.

[6] V. N. Malheiro, J. N. Skepper, R. A. Brooks, and A. E. Markaki, "In vitro osteoblast response to ferritic stainless steel fiber networks for magneto-active layers on implants," Journal of Biomedical Materials Research-Part A, vol. 101, no. 6, pp. 15881598, 2013.

[7] Z. Ting, C. Min, Y.-Y. Gao, and X.-M. Zheng, "Preparation process and characterization of new $\mathrm{Pt}$ /stainless steel wire mesh catalyst designed for volatile organic compounds elimination," Journal of Central South University of Technology (English Edition), vol. 19, no. 2, pp. 319-323, 2012.

[8] K.-J. Kim and H.-G. Ahn, "A study on utilization of stainless steel wire cloth as a catalyst support," Journal of Industrial and Engineering Chemistry, vol. 18, no. 2, pp. 668-673, 2012.

[9] R. L. Spear, R. A. Brooks, and A. E. Markaki, "Short-term in vitro responses of human peripheral blood monocytes to ferritic stainless steel fiber networks," Journal of Biomedical Materials Research Part A, vol. 101, no. 5, pp. 1456-1463, 2013.

[10] J. C. Qiao, Z. P. Xi, H. P. Tang, J. Y. Wang, and J. L. Zhu, "Influence of porosity on quasi-static compressive properties of porous metal media fabricated by stainless steel fibers," Materials \& Design, vol. 30, no. 7, pp. 2737-2740, 2009.

[11] T. W. Clyne, A. E. Markaki, and J. C. Tan, "Mechanical and magnetic properties of metal fibre networks, with and without a polymeric matrix," Composites Science and Technology, vol. 65, no. 15-16, pp. 2492-2499, 2005.

[12] A. E. Markaki, V. Gergely, A. Cockburn, and T. W. Clyne, "Production of a highly porous material by liquid phase sintering of short ferritic stainless steel fibres and a preliminary study of its mechanical behaviour," Composites Science and Technology, vol. 63, no. 16, pp. 2345-2351, 2003.

[13] P. Ducheyne, E. Aernoudt, and P. De Meester, "The mechanical behaviour of porous austenitic stainless steel fibre structures," Journal of Materials Science, vol. 13, no. 12, pp. 2650-2658, 1978.

[14] E. A. Aguilar and R. A. L. Drew, "Melt extraction processing of structural $\mathrm{Y}_{2} \mathrm{O}_{3}-\mathrm{Al}_{2} \mathrm{O}_{3}$ fibers," Journal of the European Ceramic Society, vol. 20, no. 8, pp. 1091-1098, 2000.

[15] N. I. Baik, Y. Choi, and K. Y. Kim, "Fabrication of stainless steel and aluminum fibers by PDME method," Journal of Materials Processing Technology, vol. 168, no. 1, pp. 62-67, 2005.

[16] R. de Bruyne, "Bundle-drawn metal fibers," Advanced Materials and Processes, vol. 147, no. 6, pp. 33-34, 1995.

[17] Y. Huh, B. K. Ha, and J. S. Kim, "Dieless drawing steel wires using a dielectric heating method and modeling the process dynamics," Journal of Materials Processing Technology, vol. 210, no. 13, pp. 1702-1708, 2010.

[18] Z. P. Wan, Y. Tang, and F. Y. Zhang, "On manufacturing of long stainless steel fiber with fin by multi-tooth tool and mechanical properties of the fiber," Key Engineering Materials, vol. 315-316, pp. 666-670, 2006.

[19] Y. Tang, W. Zhou, J. Xiang, W. Liu, and M. Pan, "An innovative fabrication process of porous metal fiber sintered felts with three-dimensional reticulated structure," Materials and Manufacturing Processes, vol. 25, no. 7, pp. 565-571, 2010. 

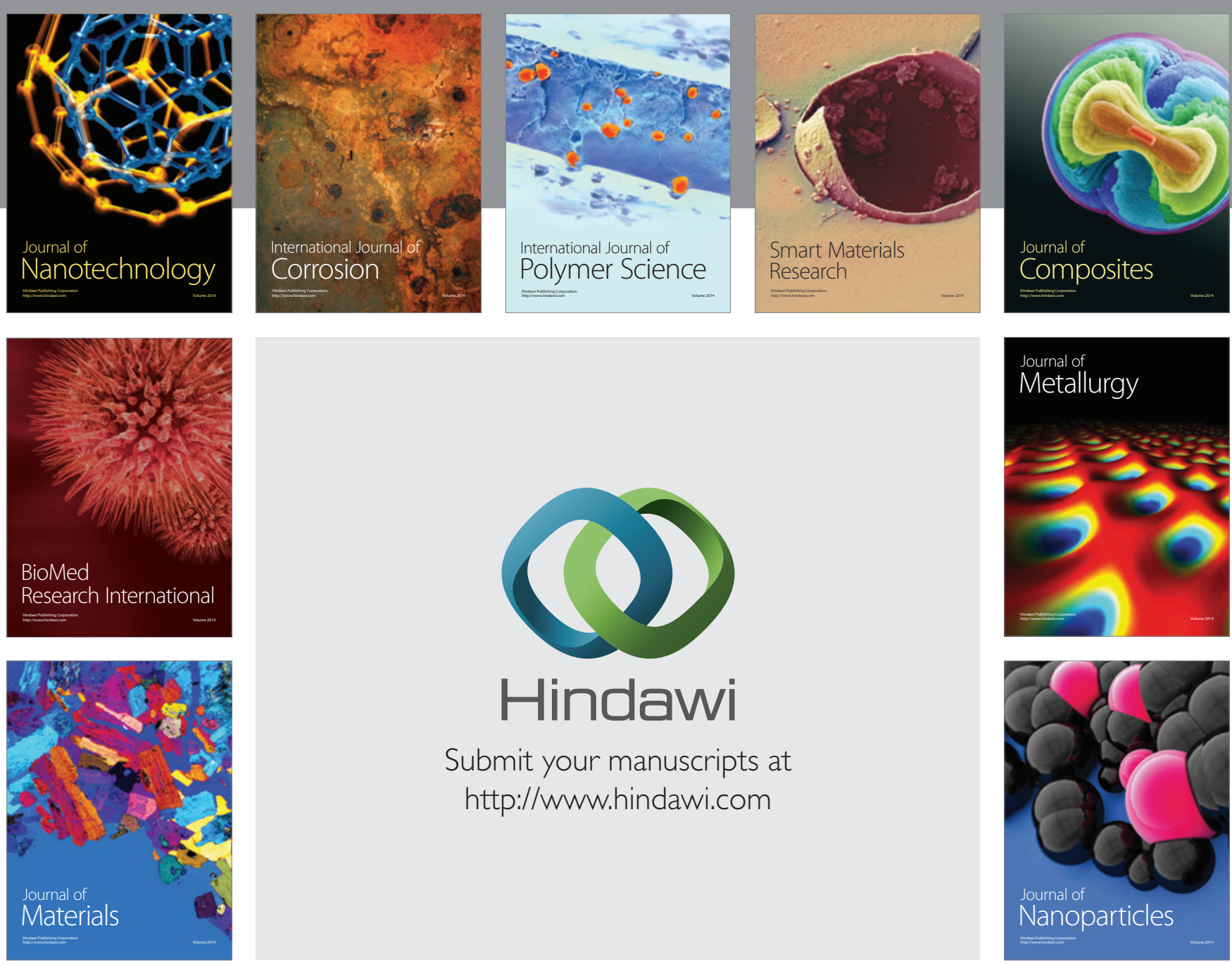

Submit your manuscripts at http://www.hindawi.com
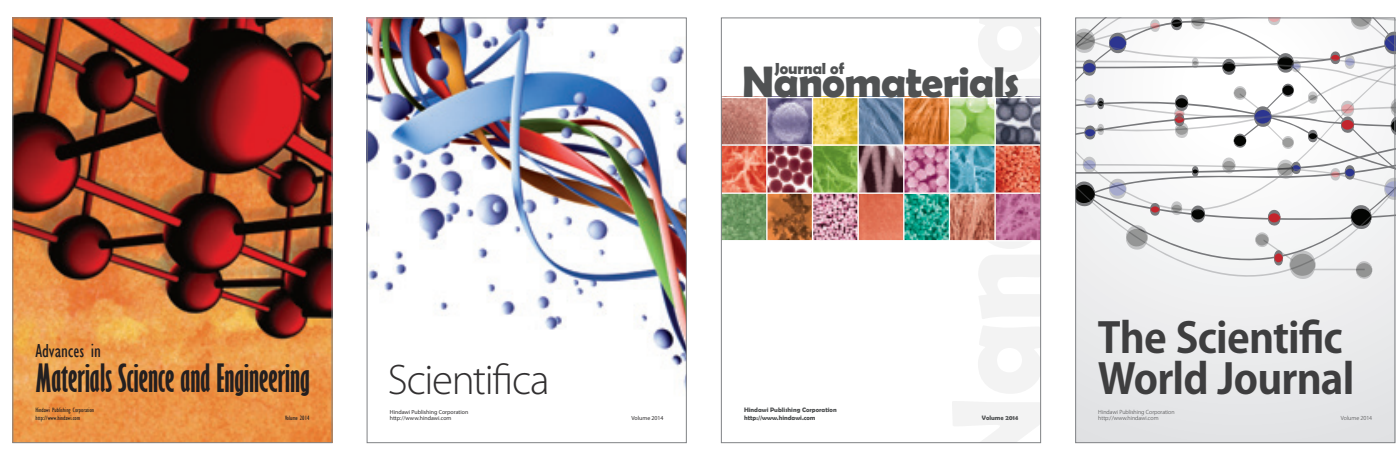

\section{The Scientific World Journal}
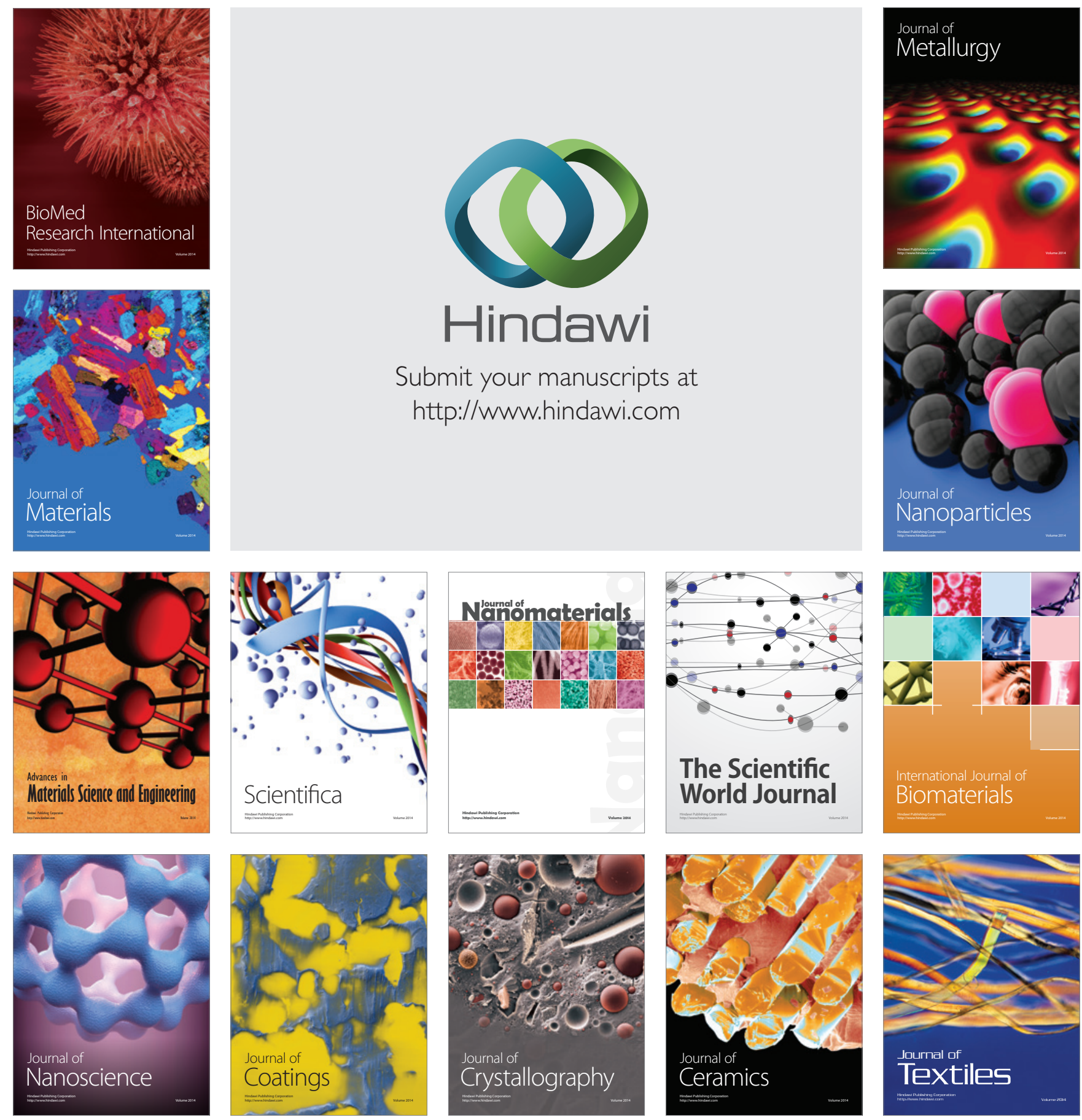